\title{
Collateral Impact of the COVID-19 Pandemic on Acute Care of Non-COVID Patients: An Internet-based Survey of Critical Care and Emergency Personnel
}

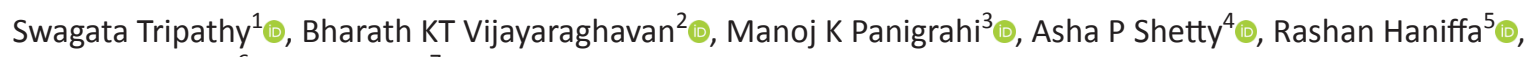
Rajesh C Mishra ${ }^{\infty}$, Abi Beane ${ }^{7}$ (1)

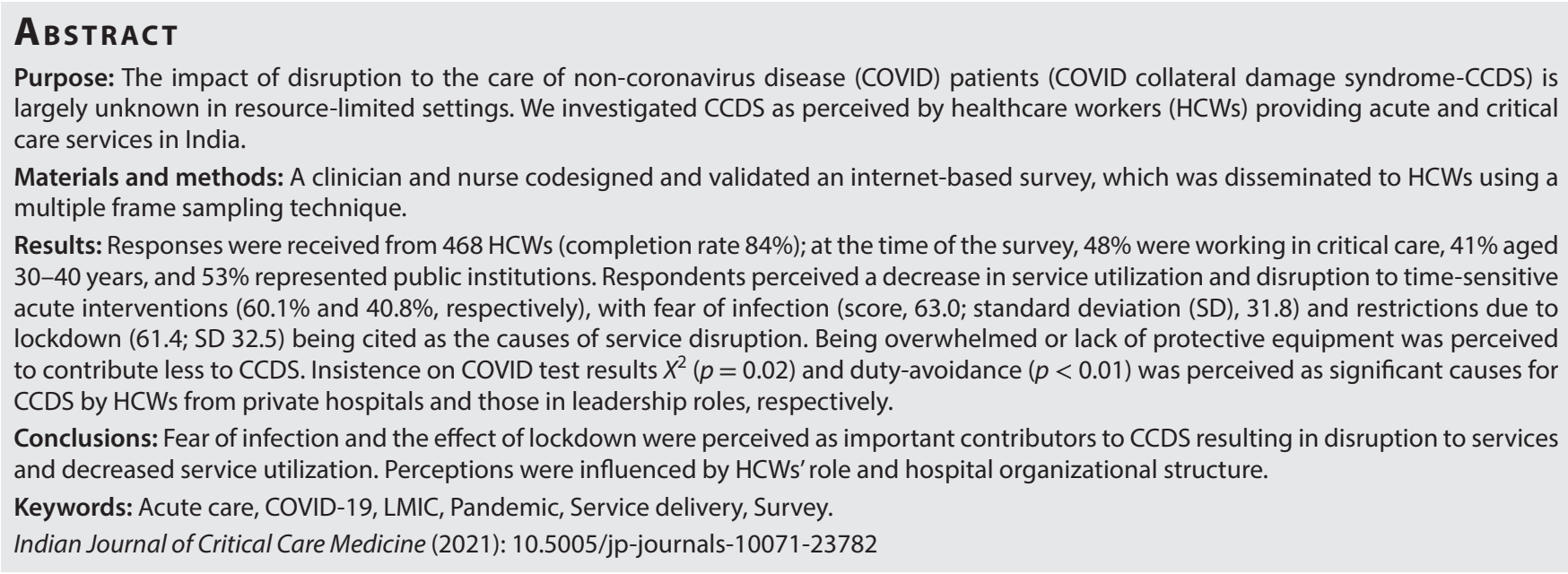

\section{BACKGROUND}

The coronavirus disease-2019(COVID-19) pandemic is unprecedented in its impact on healthcare delivery internationally. The rapidity and spread of COVID-19 have illustrated how quickly healthcare systems can be overwhelmed, including those in developed countries. ${ }^{1-3}$

Alarmed by the rapid spread of disease across Europe, countries in Asia (including India) imposed varying intensities of lockdown in order to enable healthcare services and providers to prepare for the pandemic. In India, state-led systems reprioritized healthcare services to respond to the pandemic. Tertiary hospitals with critical care resources were identified as COVID care centers, whereby resources, including respiratory therapies, personal protective equipment (PPE), and trained personnel could be deployed to the care of these patients. In these same institutions, chronic disease clinics and elective surgical care were deprioritized with staff, bed spaces, and equipment redirected. ${ }^{4}$ This restructuring of resources, and reduction in nonpandemic related interventions in India mirrored similar processes in Sri Lanka, Pakistan, Nepal, and the UK..$^{5-7}$

Similar reprioritization and redirection of healthcare resources have been described following natural disasters and previous pandemics including severe acute respiratory syndrome (SARS). However, such redirection has never been seen on such a global or massive scale. Consequently, the impact on patient care for nonpandemic patients is unknown. ${ }^{8,9}$ Termed COVID collateral damage syndrome (CCDS), this impact is a result of delay or failure
${ }^{1}$ Department of Anesthesia and Intensive Care, All India Institute of Medical Sciences, Bhubaneswar, Odisha, India

${ }^{2}$ Department of Critical Care Medicine, Apollo Hospitals, Chennai, Tamil Nadu, India

${ }^{3}$ Department of Pulmonary Medicine and Critical Care, All India Institute of Medical Sciences, Bhubaneswar, Odisha, India

${ }^{4}$ Department of Child Health Nursing, College of Nursing, All India Institute of Medical Sciences, Bhubaneswar, Odisha, India

${ }^{5}$ Mahidol Oxford Tropical Medicine Research Unit, Bangkok, Thailand

${ }^{6}$ Department of MICU, Shaibya Comprehnsive Care Clinic, Ahmedabad, Gujarat, India

${ }^{7}$ Department of Critical Care, Mahidol Oxford Tropical Medicine Research Unit, Bangkok, Thailand

Corresponding Author: Swagata Tripathy, Department of Anesthesia and Intensive Care, All India Institute of Medical Sciences, Bhubaneswar, Odisha, India, Phone: +91 8763400534, e-mail: tripathyswagata@gmail.com

How to cite this article: Tripathy S, Vijayaraghavan BKT, Panigrahi MK, Shetty AP, Haniffa R, Mishra RC, et al. Collateral Impact of the COVID-19 Pandemic on Acute Care of Non-COVID Patients: An Internet-based Survey of Critical Care and Emergency Personnel. Indian J Crit Care Med 2021;25(4):374-381.

Source of support: $\mathrm{Nil}$

Conflict of interest: None

(0) Jaypee Brothers Medical Publishers. 2021 Open Access This article is distributed under the terms of the Creative Commons Attribution 4.0 International License (https://creativecommons.org/licenses/by-nc/4.0/), which permits unrestricted use, distribution, and non-commercial reproduction in any medium, provided you give appropriate credit to the original author(s) and the source, provide a link to the Creative Commons license, and indicate if changes were made. The Creative Commons Public Domain Dedication waiver (http://creativecommons.org/publicdomain/zero/1.0/) applies to the data made available in this article, unless otherwise stated. 
to seek or receive care for acute emergencies for non-COVID-19 conditions. ${ }^{10}$

COVID-19's global footprint has meant that disruptions to non-COVID patient care are potentially magnified in low and lower-middle-income countries where limited access to and enormous variations in quality of care already result in increased morbidity and mortality. ${ }^{11}$ The impact of service reprioritization and redirection on non-COVID-19 services is as yet poorly understood. Understanding the nature and impact of such disruptions in India is key to future pandemic preparedness both in Asia and more widely in global health care. To this end, we surveyed frontline healthcare workers' (HCWs') perspectives of disruption to acute care services for non-COVID patients and the perceived causes of CCDS.

\section{Aims and Овjectives}

- To evaluate HCWs' perceptions of the impact of the COVID-19 pandemic on the delivery of acute care services for non-COVID patients.

- To identify the perceived reasons for a change in acute care provision.

- To identify how these perceptions were influenced by HCWs and healthcare institutional characteristics.

\section{Materials and Methods}

\section{Study Design}

Using participatory research methods, an internet-based survey was codesigned and produced by a working group of acute and critical care clinicians and nursing officers. The survey sought to capture HCWs' perspectives of (1) changes in the availability, access, and uptake of acute care services for non-COVID patients, (2) the perceived reasons for such changes in service provision (including fear of services being overwhelmed, service reorganization, fear of contracting COVID-19 infection, delay in test reports, and lockdown affecting access to health care), and (3) changes in behavior and duty of care among HCWs during the pandemic.

To enable understanding of the influence that HCW roles, experience, and organizational structure may have had on these perspectives, the survey also collated respondent characteristics and the characteristics of their place of work.

Responses to questions were either using multiple choice or Likert scales. The respondents were asked to prioritize their perception of how important the different contributory causes were to CCDS using a visual analog scale where responses ranged between 0 and 100; (with zero being "disagree totally" and 100 being "agree completely"). Where possible, free-text responses were minimized to facilitate analysis and reliability of interpretation.

Questions were ordered in such a sequence as to promote relevance and logic between them. Respondents were able to review and change their answers before final submission. A participant information sheet administered along with the survey detailed the survey aims, eligibility for participation, responder involvement, and consent (Supplement 1, the Survey Questionnaire).

Twenty-four questions were piloted for salience, sequence, and response sensitivity and reliability. Inter-rater reliability was established. Face value was determined by administering the survey to a nonacute care medical clinician and a statistician. In addition, pilot responders were asked to comment on usability and ease of completion of the electronic survey. Assessment of internal consistency demonstrated excellent reliability (Cronbach's alpha-0.87): deletion of any survey component questions decreased reliability; therefore, all questions and response options were retained. Exploratory factor analysis revealed that the three-component structure for causes of CCDS (an overwhelmed healthcare system, lockdown, and fear of the pandemic) accounted for $71 \%$ of the total variance.

\section{Recruitment and Respondents}

The survey was conducted over three weeks (May 28 to June 19, 2020), during which periods of public lockdown and "unlock" were experienced. Invitation to join the survey was sent to HCWs via professional and personal contacts through email, invitation-only online communication platforms, and through the hospital and institutional intranets. HCWs (doctors, nurses, allied healthcare professionals) caring for acutely unwell patients during the pandemic were invited. No incentives were offered. The study was endorsed by professional bodies: Indian Registry of Intensive Care, ${ }^{12}$ a member of Crit Care Asia, ${ }^{13}$ the Indian Society of Critical Care Medicine, ${ }^{14}$ the official critical care body of India, and the Critical Care Nurses Society. ${ }^{15}$

A multiple frame sampling technique combining simple sample frames from separate email lists was used. First, emails were sent in a phased manner to groups of intensivists, pulmonary physicians, emergency physicians, nursing societies, allied workers (technicians), and resident doctors working in acute and critical care services. As a second step, individual web links were also distributed to team leaders (consultants, nurses, technicians, and resident doctors) known to the researchers with a request for dissemination to HCWs in their respective teams. The survey was disseminated using a virtual platform (Survey Monkey). ${ }^{16}$ Only participants who were sent the email or the web link to the survey could access and submit a response.

\section{Data Quality}

Web-based anonymized surveys enable the collection of a large number of responses across different locations while minimizing social desirability bias. ${ }^{17}$ We used several strategies to optimize response validity. Web internet protocol addresses were monitored to avoid duplicate responses, and proprietary code prevented automated entries by "bots." To hold the respondents' attention and reduce the potential for repetitive pattern selection, questions and response types were varied throughout the survey (Likert and multiple choice). Response to questions was mandatory, ensuring completeness of data. Messages displayed at the end of each page alerted respondents to incomplete or invalid responses. The time taken to read the questions and complete the survey was measured during the pilot, and a threshold of exclusion set (4 minutes), below which responses were considered potentially unreliable and were excluded from the analysis. Reminders were sent after 2 days to nonresponders and responders who had commenced but not completed the survey. Reminders were subsequently repeated at five and seven days to maximize completion.

\section{Data Analysis}

Descriptive statistics were used to report respondent characteristics. Data were represented as mean (standard deviation (SD)) or median (interquartile range) for continuous variables and as percentages for categorical variables. Nonparametric tests (Kruskal Wallis $\mathrm{H}$ ) were used to estimate associations between categories of HCWs and their perception scores. Chi-square tests were used to assess the differences in perceived causes for avoidance behavior, change in patient load, and disruption of time-sensitive interventions among 
HCWs of different categories. Multivariable regression analyses were performed to explore independent associations between respondent characteristics, their organizations, and responses. All variables and outcomes were predefined, and baseline characteristics were compared between complete and partial responders to investigate possible nonresponse bias. Statistical correction (Bonferroni's) was used for multiple comparisons, and an adjusted $p$-value $<0.05$ was considered significant.

\section{Ethics}

Ethics approval for the study was obtained from the Institutional Ethics Committee of the All India Institute of Medical Sciences, Bhubaneswar, India (EC approval number: T/IM-NF/Anesth/20/18).

\section{Results}

\section{Response Rate}

A total of 1157 emails elicited 326 responses (response rate (RR) 28\%) and 302 web links resulted in 142 responses (RR 47\%), giving a combined overall RR of $32.1 \%$. Of the 468 responses, 76 were excluded due to duplication, incompleteness, or cutoff from the minimum time threshold for completion, resulting in a total of 392 complete responses being included in the analysis (completion rate $84 \%, n=468$ ).

\section{Respondents}

Majority of respondents (41\%) were aged between 30 to 40 years. Consultant physicians contributed to $53.4 \%$ of respondents. The private to public institutions ratio was $0: 83$. 10.9\% of respondents worked in a "COVID-19 designated hospital," which was defined as institutions where patients with confirmed COVID-19 infection were referred to from other hospitals. Patients testing negative for COVID-19 would be transferred out of such facilities. Characteristics of all the respondents and their workplace institutions are described in Table 1. A flow chart of participant recruitment and exclusions is displayed in Flowchart 1. Complete and partial responders are compared in Supplement 2.
Table 1: Respondent characteristics

\begin{tabular}{|c|c|}
\hline Characteristic & $\%(n)$ \\
\hline \multicolumn{2}{|l|}{ Age (years) } \\
\hline$<30$ & $28.4 \%(133)$ \\
\hline $30-40$ & $41.0 \%(192)$ \\
\hline $41-50$ & $18.4 \%(86)$ \\
\hline $51-60$ & $8.1 \%(38)$ \\
\hline$>60$ & $4.1 \%(19)$ \\
\hline \multicolumn{2}{|l|}{ Work experience (years) } \\
\hline$<1 \quad<$ & $17.3 \%(81)$ \\
\hline Up to 5 & $29.5 \%(138)$ \\
\hline Up to 10 & $16.9 \%(79)$ \\
\hline$>10$ & $36.3 \%(170)$ \\
\hline \multicolumn{2}{|l|}{ Role at workplace } \\
\hline Physician (consultant) & $53.4 \%(250)$ \\
\hline Nurse & $14.1 \%(66)$ \\
\hline Junior physician (trainee) & $26.9 \%(126)$ \\
\hline Allied healthcare professional & $5.6 \%(26$ \\
\hline \multicolumn{2}{|l|}{ Administrative/leadership role } \\
\hline Yes & $50.6 \%(237)$ \\
\hline No & $49.4 \%(231)$ \\
\hline \multicolumn{2}{|l|}{ Place of work during the pandemic } \\
\hline ICU or HDU & $47.6 \%(223)$ \\
\hline Emergency area & $32.1 \%(150)$ \\
\hline $\begin{array}{l}\text { Nonacute area turned into an acute area in the } \\
\text { pandemic }\end{array}$ & $20.3 \%(95)$ \\
\hline \multicolumn{2}{|l|}{ Type of hospital } \\
\hline Public and teaching & $51.5 \%(241)$ \\
\hline Private and teaching & $32.1 \%(150)$ \\
\hline Not for profit & $1.1 \%(5)$ \\
\hline Public and nonteaching & $2.4 \%(11)$ \\
\hline Private and nonteaching & $13.0 \%(61)$ \\
\hline \multicolumn{2}{|l|}{ Designation of the hospital during the pandemic } \\
\hline Designated COVID-19 hospital & $10.9 \%(51)$ \\
\hline Mixed center & $35.0 \%(164)$ \\
\hline Non-COVID centers & $50.2 \%(235)$ \\
\hline Designation varied in the pandemic & $3.8 \%(18)$ \\
\hline
\end{tabular}

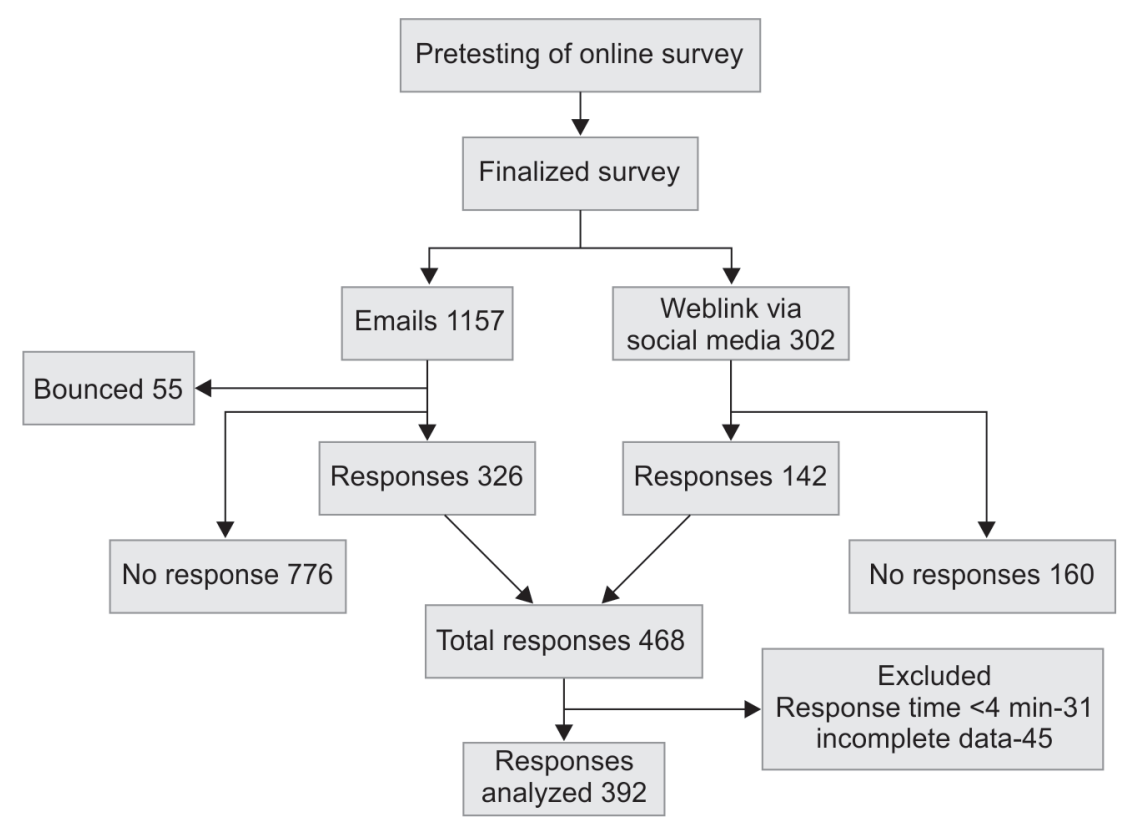

Flowchart 1: Coll COVID survey flow 


\section{Utilization of Acute Care Services}

The majority of HCWs surveyed (60.1\%) perceived a "substantial decrease" in patients accessing hospitals. This was most prominent in outpatient and elective surgery services, where $83.8 \%$ and $83.4 \%$ of respondents reported a substantial decrease, respectively. In emergency-surgical and acute medical care services, these perceptions were less prominent, with $44.8 \%$ and $38.3 \%$ of respondents reporting "substantial decrease," respectively (Fig. 1). Forty-one percent of HCWs perceived that time-sensitive interventions such as cardiac catheterization and stroke therapies for acutely ill non-COVID patients were affected during the pandemic (Fig. 2).

\section{Perceived Reasons for Changes in Service Provision and Utilization}

Lockdown and fear of infection or associated stigma were the two most frequently reported reasons (58\%) for the decrease in service utilization (Fig. 3). These perceptions were described by HCWs working in both COVID-19 and non-COVID-19 designated centers. Conversely, $22.2 \%$ of respondents reported an increase in patients coming to their hospital due to "other centers having converted to designated COVID-19 hospitals."

Disruptions to time-sensitive interventions were perceived most often to be caused by hospitals insisting on a COVID-19 negative reverse transcription polymerase chain reaction (RTPCR) report $(54.4 \%, n=160)$. "Services being limited as a part of planned restructuring for pandemic preparedness" accounted for an additional $48.1 \%(n=160)$ of responses. These are described in Figure 4

Regarding different causes contributing to CCDS, fear due to confusion (due to concern over sensitivity of RTPCR, quality of PPE, and frequently changing guidelines) was ranked by respondents as most important (mean, 63.0; SD, 31.8). "Delay in patients' access to health care due to the lockdown" (mean, 61.4; SD, 32.1)

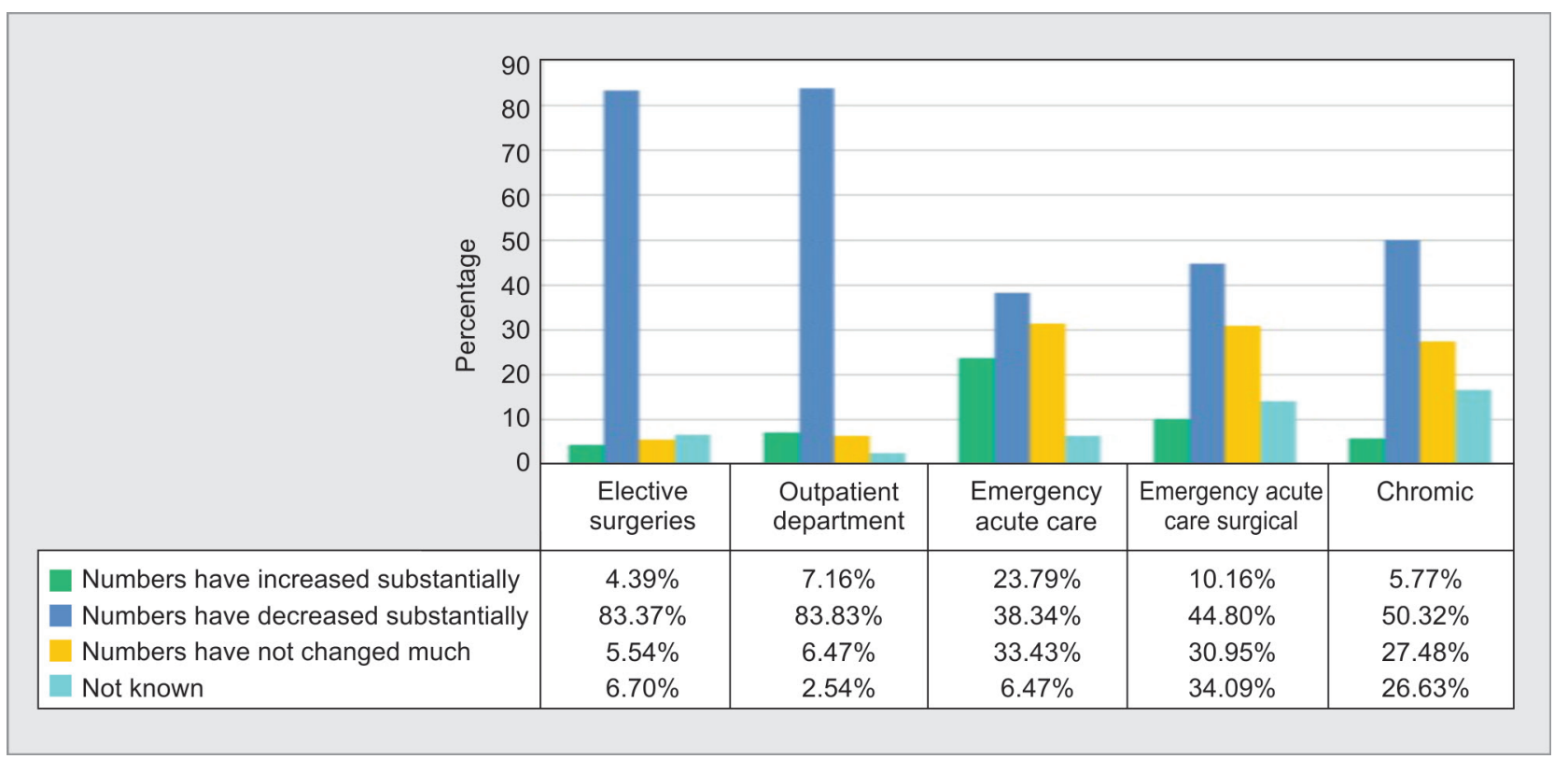

Fig. 1: Perceived changes in utilization of healthcare services

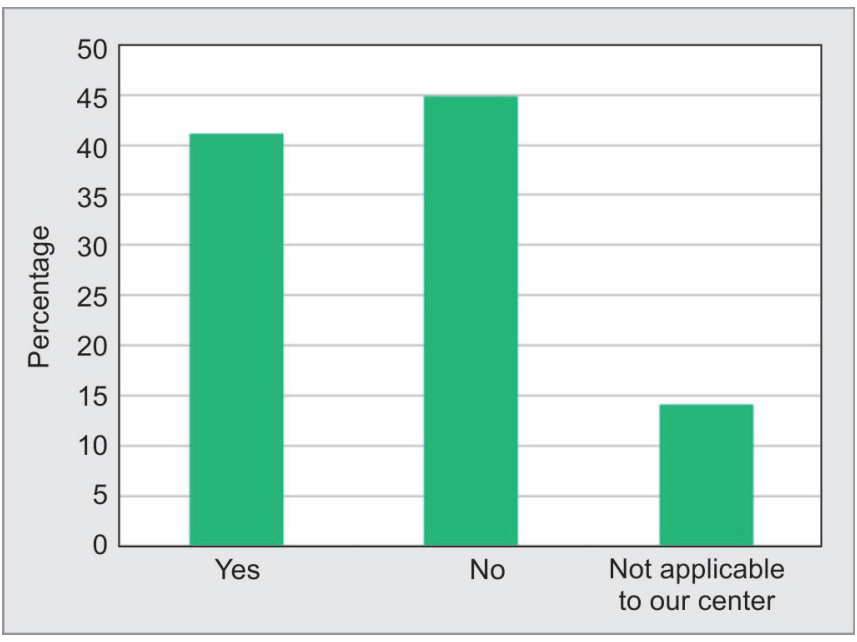

Fig. 2: Perceived disruptions to time-sensitive interventions such as cardiac catheterization and stroke therapy for non-COVID patients

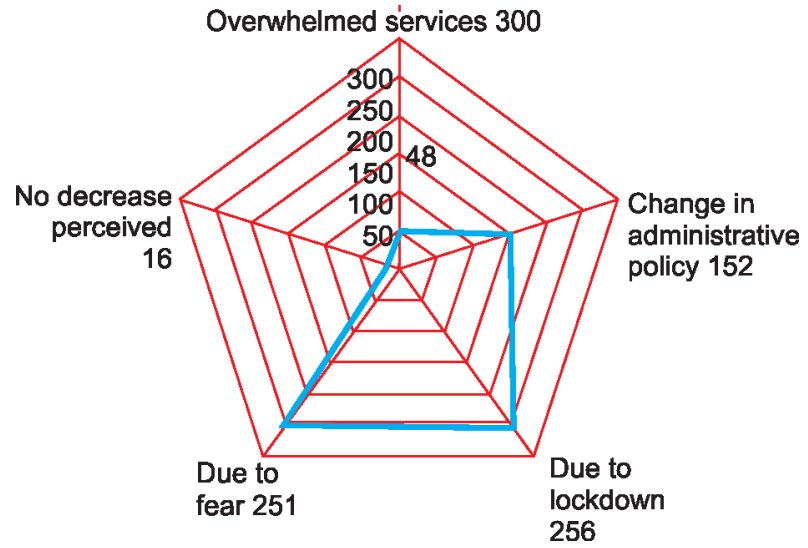

Fig. 3: Perceived causes for decrease in patient visits to the hospital 


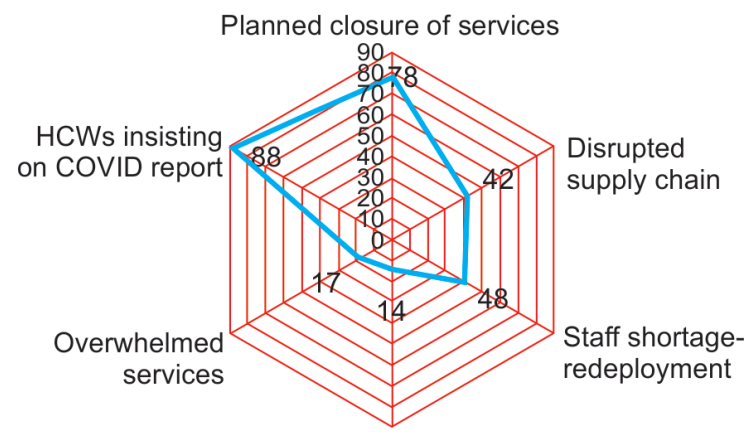

Staff shortage-sickness

Fig. 4: Perceived causes for disruption to time-sensitive interventions

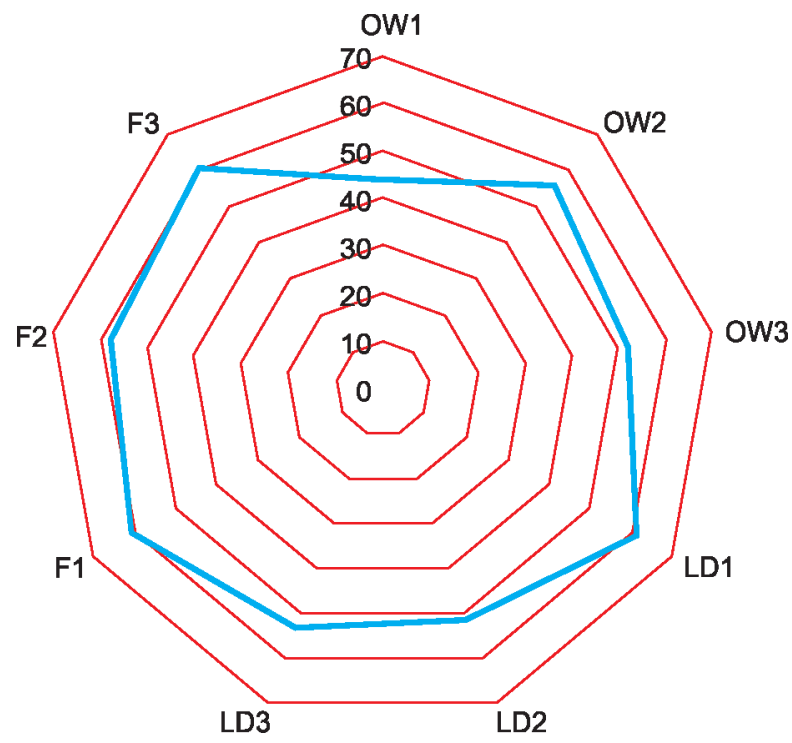

Fig. 5: Perceived importance of different causes of collateral harm to the non-COVID patient during the pandemic OW (overwhelmed) 1qualified manpower and/or equipment getting diverted for COVID-19 patient care, causing suboptimal care of non-COVID patients. OW2delay in availability of test results for COVID "suspect" patients affecting the timeliness and quality of patient care. OW3 - administrative decision to shut or limit elective services (like outpatient and elective theater) resulting in patients arriving later in the course of illness resulting in greater morbidity and mortality. LD (lockdown) 1-delay in the patient having access to health care or reaching your center due to effects of the lockdown. LD2 - quality of care being affected due to a break in the supply chain of drugs and consumables (including PPE) as a result of rationing during the lockdown. LD3-acute complications due to decreased access to chronic care such as pain/palliation/dialysis/ chemotherapy during the lockdown. F (Fear) 1-delay in the patient presenting to the health center for the fear of contracting COVID-19 or testing positive resulting in societal stigma. F2 - fear of patient being COVID positive leading to delay in, or suboptimal care in patients presenting to the hospital with tachypnea and fever such as patients with sepsis, angina, diabetic ketoacidosis, exacerbation of COPD, etc. F3-fear, confusion, and misinformation regarding COVID

ranked second, followed by perceptions of fear among patients of contracting infection and the stigma of testing positive, resulting in delayed presentation to the hospital (mean, 60.8; SD 33.3). HCWs' perceptions of the importance of causes of CCDS are described in Figure 5. Supplement 3 shows the causes of CCDS as perceived by different groups of HCWs.
Table 2: Perceptions of HCW behavior

\begin{tabular}{lll}
\hline Perceived HCW behavior & Yes \% (n) & No \% (n) \\
\hline $\begin{array}{l}\text { Avoiding duty for fear of infecting self } \\
\text { (in spite of PPE suitable to the type of } \\
\text { exposure) }\end{array}$ & $50.5 \%(198)$ & $49.5 \%(194)$ \\
$\begin{array}{l}\text { Avoiding duty for fear of infecting } \\
\text { elderly parents or family members }\end{array}$ & $60.2 \%(236)$ & $39.8 \%(156)$ \\
$\begin{array}{l}\text { Recusing duty if of age more than } \\
60 \text { years }\end{array}$ & $57.6 \%(226)$ & $42.3 \%(166)$ \\
\hline
\end{tabular}

\section{Perceptions of HCW Behavior in the Pandemic}

More than half of the surveyed HCWs (56.1\%) reported having observed avoidance of duty of care to patients among colleagues. Factors thought to underpin this observed behavior were fear for own health (50.5\%), fear for the health of the family $(60.2 \%)$, and avoidance of duty by HCWs aged more than 60 years $(57.7 \%$, Table 2$)$.

\section{Impact of Institution and Respondent Characteristics on HCWs Perspectives}

Designation as a COVID-19 only, non-COVID, or a mixed hospital did not impact the perceptions of HCWs on service utilization, the impact on the timeliness of services, or the perceived causes of CCDS. HCWs from private centers were more likely to report a substantial decrease in the number of patients visiting the emergency medicine $\left(X^{2}(3,392)=25.2, p \leq 0.01\right)$, emergency surgery $\left(X^{2}(3,392)=30.9, p \leq 0.01\right)$, outpatient $\left(X^{2}(3,392)=9.8\right.$, $p=0.02)$, and elective surgery $\left(X^{2}(3,392)=8.3, p=0.04\right)$ areas, when compared to respondents from public hospitals.

For time-sensitive procedures, the mandatory requirement of a COVID-19 test report was perceived as a significant cause of disruption by HCWs from private centers $\left(X^{2}(4,392)=12.2, p=0.02\right)$. It was also perceived as a significant cause of disruption to care by HCWs working in intensive care units (ICUs) and high dependency units (HDUs): $\left(X^{2}(2,392)=22.2, p=0.00\right)$ than in other acute areas.

Perceptions of the importance of causes of CCDS differed within age groups, $\mathrm{HCW}$ roles, and organizational structure (Table 3 ).

All HCWs regardless of role, seniority, organizational structure reported witnessing avoidance behavior due to fear of infecting family members $(p>0.05)$. Having a leadership position at work was associated with a higher chance of having witnessed HCWs avoiding duty despite appropriate PPE $\left(X^{2}(1,392)=8.6, p<0.01\right)$ or recusing themselves if of age more than 60 years $\left(X^{2}(1,392)=17.2, p<0.01\right)$.

\section{Discussion}

Our survey describes HCWs' perceptions of the disruption of acute care for non-COVID patients during the COVID-19 pandemic from multiple healthcare facilities across India. Acute care services were perceived to be disrupted for non-COVID patients. The causes of this disruption were "fear of contracting infection" and "impact of lockdown," which was perceived to impact both patients and HCWs. "Services being overwhelmed" and "limitations in resources" were not seen as drivers of disruption in care at the time this survey was conducted. A delay in the availability of COVID-19 test results was perceived to disrupt time-sensitive procedures, especially by HCWs from private hospitals and those working in ICUs. HCWs in positions of leadership within their institution were more likely to report avoidance behavior among their colleagues, although respondents from all cross sections of profession, and organizations reported the phenomenon. 
Table 3: Difference in perceptions across different categories

\begin{tabular}{|c|c|c|c|c|c|}
\hline Variable & Categories & $\begin{array}{l}\text { Question with } \\
\text { difference scores }\end{array}$ & $P$ value & $\begin{array}{l}\text { Significant pairwise } \\
\text { comparison }\end{array}$ & $\begin{array}{l}\text { Adjusted } \\
\text { significance }\end{array}$ \\
\hline Age & $\begin{array}{l}1=<30 \text { years } \\
2=30-40 \text { years } \\
3=41-50 \text { years } \\
4=51-60 \text { years } \\
5=>60 \text { years }\end{array}$ & $\begin{array}{l}\text { OW1 } \\
\text { OW3 } \\
\text { LD2 } \\
\text { LD3 } \\
\text { F1 }\end{array}$ & $\begin{array}{l}0.02 \\
0.04 \\
0.01 \\
0.05 \\
0.05\end{array}$ & $\begin{array}{l}5-1 \\
5-2 \\
5-1 \\
5-2 \\
- \\
- \\
-\end{array}$ & $\begin{array}{l}0.02 \\
0.03 \\
0.02 \\
0.04 \\
- \\
- \\
-\end{array}$ \\
\hline Role & $\begin{array}{l}1=\text { Physician } \\
2=\text { Nurse } \\
3=\text { Junior physician (trainee) } \\
4=\text { Allied HCW }\end{array}$ & $\begin{array}{l}\text { OW1 } \\
\text { LD1 } \\
\text { F2 }\end{array}$ & $\begin{array}{l}0.04 \\
0.00 \\
0.04\end{array}$ & $\begin{array}{l}1-3 \\
1-3 \\
1-4 \\
2-3 \\
2-4 \\
2-3\end{array}$ & $\begin{array}{l}0.04 \\
0.04 \\
0.03 \\
0.01 \\
0.005 \\
0.04\end{array}$ \\
\hline Place of work & $\begin{array}{l}1=\text { ICU OR HDU } \\
2=\text { Emergency area or theatre } \\
3=\text { Nonacute area converted } \\
\text { to an acute area }\end{array}$ & LD1 & 0.04 & $2-3$ & 0.04 \\
\hline Type of HCC & $\begin{array}{l}1=\text { Govt, teach } \\
2=\text { Pvt, teach } \\
3=\text { Not for profit } \\
4=\text { Govt }, \text { nonteach } \\
5=\text { Private nonteach }\end{array}$ & OW3 & 0.03 & - & - \\
\hline
\end{tabular}

There was no difference in perceptions across groups across "experience," "leadership," and "being a designated COVID center;" HCC: healthcare centre

\section{Utilization of Services}

The impact of the COVID-19 pandemic on non-COVID patients accessing acute care services in resource-constrained settings is largely unknown. Underutilisation of healthcare services for HIV, malaria, and tuberculosis programs during the Ebola outbreak in West Africa has been previously described $;{ }^{18}$ these previously reported public health emergencies have dominated community and primary health. In contrast, the COVID-19 pandemic has brought into public consciousness the importance of acute and critical care services during public health emergencies. The perceived decrease in non-COVID patients, notably in outpatient and elective surgeries followed by emergency procedures widely reported by study respondents mirrors the literature from the SARS pandemic and the MERS outbreak. ${ }^{19-21}$

\section{Fear of Infection}

The fear of getting infected and the stigma of quarantine, as reported here, were described during the Ebola pandemic in West Africa and SARS in South East Asia. ${ }^{18,22}$ Other reported causes of fear in pandemics had been the frequently changing public health guidelines, extensive access to mainstream and social media reporting, and an "infodemic" of inaccurate information. ${ }^{23,24}$

In this study, $65 \% \mathrm{HCW}$ s reported having witnessed colleagues avoiding duties for the fear of infecting family. The behavior was universal across ages, roles, and types of HCWs. This is not a new finding: $\mathrm{HCWs}$ are reported to have refused to care for patients and resigned their positions during the SARS pandemic. ${ }^{25}$ Psychological trauma, stigma from housing societies, and pressure to be "heroes" from the media are reported causes of physician and HCW stress during pandemics. ${ }^{26,27}$
The ethicality of HCWs providing care (at risk to self) during pandemics is debated. ${ }^{25} \mathrm{~A}$ significant difference between leaders and "workers," about the morality of "duty" during pandemics, however, may lead to a clash of interests that can worsen the CCDS scenario. ${ }^{28}$ This finding unreported previously needs to be explored further.

\section{Lockdown}

The scale, duration, and impact of lockdowns during this current pandemic have been unprecedented. Mathematical projections, estimating the effectiveness of lockdowns, have neglected to describe or consider the effect on the care of the acutely ill non-COVID patient. ${ }^{3}$ The lockdown has affected acute care, hematology, immunization, maternal care services, and supply chains the world over. ${ }^{29-33}$ The inability of patients to reach the hospital during the lockdown was perceived as an important cause of CCDS by HCWs surveyed.

COVID-19 tests: A majority of HCWs felt that the insistence on COVID-19 negative tests was responsible for CCDS. HCWs from private hospitals perceived this to be of greater significance than those from public hospitals. State policies in India in the early phase of the pandemic had limited RTPCR testing to select government laboratory facilities. ${ }^{34}$ Eventually, when access to testing was expanded, the cost was often prohibitive for many institutions. Rapid antigen testing with its higher false-negative results was available only towards the later parts of this survey. ${ }^{35}$ As perceived by HCWs, without ready access to point of care or PCR testing, HCWs and patients struggled to provide sufficient evidence of their infection status, precluding or delaying their access to acute care, more so in private institutions, in ICUs, and for time-sensitive interventions. 
Strengths: Our strengths include the choice of an electronic survey to shorten response times for $\mathrm{HCW}$ s facing competing demands on their time and possible survey fatigue. ${ }^{36}$ More than $84 \%$ of respondents left no question unanswered: the electronic platform enabled us to prevent multiple responses by the same $\mathrm{HCW}$, to check for completion validity, and to improve completion rates by sending reminders. We deleted all incomplete or "rogue" responses, i.e., those filled carelessly, by filtering by the time taken to submit the questionnaire, ${ }^{37}$ and followed the CHERRIES guidelines for reporting our methodology. ${ }^{38}$

Limitations: Sampling bias, volunteer effect, and inadequate reporting are known limitations of surveys. ${ }^{39}$ We adopted a closed survey style and involved diverse groups of HCWs to reduce "volunteer effect," selection bias, and improve external validity. While our survey provides important insights on disruptions to non-COVID care from the viewpoint of HCWs working in acute and critical care settings, more work is needed to objectively evaluate the impact on such disruptions, specifically for oncology, surgical, and cardiology services, for which timely intervention is directly associated with reducing morbidity and mortality. ${ }^{29,40}$ Work is underway from this group in quantifying the impact of the pandemic on ICU service utilization using a multicenter critical care registry.

\section{Conclusion}

CCDS was perceived by HCWs involved in acute care of nonCOVID patients during the pandemic. Disruption to provision and utilization of services were felt to be caused by fear of contracting the infection and the impact of the lockdown. HCWs reported a change in colleagues' behavior, further affecting the quality of services. Future research from both high-income and low-income settings will help inform the public health response and national policies in dealing with nonpandemic illnesses during such periods of intense healthcare system strain.

\section{Declarations}

Ethics approval and consent to participate: Ethics approval from Institute ethics Committee of AlIMS Bhubaneswar and consent to participate in the survey was a part of the survey instrument.

Consent for publication: Available.

Availability of data and materials: Will be made available by the corresponding author on reasonable request

Competing interests: None to declare

Funding: No sources of funding.

Authors' contributions: CRediT author statement. ST, BKTV, AB: conceptualization, methodology, software. MKP, AS, ST, BKTV, RM, $A B$ : Data curation. Writing: original draft preparation, visualization, investigation. $A B, R H, R M$ : supervision. $S T, B K T V, A B, A S, M K P, R H$ : Writing-reviewing and editing

\section{ORCIDS}

Swagata Tripathy (1) https://orcid.org/0000-0002-5315-6477 Bharath KTVijayaraghavan (i) https://orcid.org/0000-0002-1801-0667 Manoj K Panigrahi (ib https://orcid.org/0000-0002-2743-1068 Asha P Shetty (1) https://orcid.org/0000-0001-5438-4722 Rashan Haniffa @ https://orcid.org/0000-0002-8288-449X Rajesh C Mishra @ https://orcid.org/0000-0001-6305-5998 Abi Beane 아 https://orcid.org/0000-0001-7046-1580

\section{Supplementary Material}

Supplement 1: Survey instrument

Supplement 2: Comparison between complete and partial responders

Supplement 3: Radar charts showing difference in perceptions among HCWs based on demographic parameters

\section{References}

1. Levin PJ, Gebbie EN, Qureshi K. Can the health-care system meet the challenge of pandemic flu? Planning, ethical, and workforce considerations. In: Public health reports, vol. 122. Washington, DC: Association of Schools of Public Health; 2007, pp. 573-578.

2. Duley MGK. The next pandemic: anticipating an overwhelmed health care system. Yale J Biol Med 2005;78:355-362. DOI: 10.1016/j. jaip.2020.03.012

3. Chatterjee K, Chatterjee K, Kumar A, Shankar S. Healthcare impact of COVID-19 epidemic in India: a stochastic mathematical model. Med J Armed Forces India 2020;76(2):147-155. DOI: 10.1016/j. mjafi.2020.03.022.

4. The Lancet. India under COVID-19 lockdown. Lancet 2020;395(10233): 1315. DOI: 10.1016/S0140-6736(20)30938-7.

5. Over 580,000 surgeries in India may be cancelled due to COVID-19: study. The Economic Times. Available from: https://economictimes. indiatimes.com/industry/healthcare/biotech/healthcare/covid19-pandemic-will-lead-to-over-28-million-cancelled-surgeriesworldwide-study/articleshow/75757140.cms. Accessed 25 August 2020.

6. Atif M, Malik I. Why is Pakistan vulnerable to COVID-19 associated morbidity and mortality? A scoping review. Int J Health Plann Manage 2020; 35(5):1041-1054. DOI: 10.1002/hpm.3016.

7. De Guzman R, Malik M. Dual challenge of cancer and COVID-19: Impact on health care and socioeconomic systems in Asia Pacific. JCO Glob Oncol 2020;(6):906-912. DOI: 10.1200/GO.20.00227.

8. Malina D, Rosenbaum L. The untold toll-the pandemic's effects on patients without Covid-19. 2020.

9. Galarza M, Gazzeri R. Letter: Collateral pandemic in face of the present COVID-19 pandemic: a neurosurgical perspective. Neurosurgery 2020;87(2):E186-E188. DOI: 10.1093/neuros/nyaa155.

10. Date P. First do no harm with COVID-19: corona collateral damage syndrome. West J Emerg Med 2020;21(4):746-747. DOI: 10.5811/ westjem.2020.5.48013.

11. Chandir S, Siddiqi DA, Setayesh H, Khan AJ. Impact of COVID-19 lockdown on routine immunisation in Karachi, Pakistan. Lancet Glob Health 2020;8(9):e1118-e1120. DOI: 10.1016/S2214-109X(20)30290-4.

12. IRIS ICU Registry. Available from: http://www.irisicuregistry.org/. Accessed 1 August 2020.

13. CRIT CARE ASIA. Establishing a critical care network in Asia to improve care for critically ill patients in low- and middle-income countries. Crit Care 2020;24:608. DOI: 10.1186/s13054-020-03321-7.

14. Indian Society of Critical Care Medicine. Available from: https://isccm. org/. Accessed 31 December 2020.

15. Critical Care Nurses Society. Critical care nursing society. Available from: http://www.criticalcarenursessociety.com/. Accessed 31 December 2020.

16. SurveyMonkey. Free online survey software and questionnaire tool. Available from: https://www.surveymonkey.com/welcome/sem/ ?program $=7013 \mathrm{~A} 000000 \mathrm{mweBQAQ} \& u t \mathrm{tm}$ bu $=\mathrm{CR} \& u$ tm_campaign $=$ 71700000059186490\&utm_adgroup $=58700005408390198 \& u$ tm $_{-}$ content $=43700049188951718 \&$ utm_medium $=c p c \& u t m \_s o u r c e=$ adwords\&utm_term $=p 49188951718 \& u t m \_k x c o n f i d=s 4 b v p i 0 j u \&$ language $=\& g$ clid $=$ CjwKCAiAirb_BRBNEiwALHInDyoLz0okLa106X wrlpn92IAErArOXyywGQGId-JKuZkUGVKbhLKmPRoCuvAQAvD_ BwE\&gclsrc=aw.ds. Accessed 31 December 2020.

17. Eysenbach G, Wyatt J. Using the Internet for surveys and health research. J Med Internet Res 2002; 4:76-94. DOI: 10.2196/jmir.4.2.e13. 
18. Wilhelm JA, Helleringer S. Utilization of non-Ebola health care services during Ebola outbreaks: a systematic review and meta-analysis. J Glob Health 2019;9(1):010406. DOI: 10.7189/jogh.09.010406.

19. Yalamanchi $R$, Chandra Dasari B, Narra L, Oomman A, Kumar $P$, Nayak R, et al. Cardiac intensive care unit admissions during COVID19 pandemic-a single center experience. Indian J Crit Care Med. 2020;24(11):1103-1105. DOI: 10.5005/jp-journals-10071-23660.

20. Lu TH, Chou YJ, Liou CS. Impact of SARS on healthcare utilization by disease categories: implications for delivery of healthcare services. Health Policy 2007;83(2-3):375-381. DOI: 10.1016/j. healthpol.2007.03.001.

21. Lee SY, Khang YH, Lim HK. Impact of the 2015 middle east respiratory syndrome outbreak on emergency care utilization and mortality in South Korea. Yonsei Med J 2019;60(8):796-803. DOI: 10.3349/ ymj.2019.60.8.796.

22. Ebola T, Africa W. CMI BRIEF Ebola outbreak 2014-2016, vol. 3. Bergen: CMI Brief; 2020.

23. Li W, Yang Y, Ng CH, Zhang L, Zhang Q, Cheung T, et al. Global imperative to combat stigma associated with the coronavirus disease 2019 pandemic. In: Psychological medicine. Cambridge: Cambridge University Press; 2020. p. 1.

24. Lazzerini M, Barbi E, Apicella A, Marchetti F, Cardinale F, Trobia G. Delayed access or provision of care in Italy resulting from fear of COVID-19. Lancet Child Adolesc Health 2020;4:e10-e11. DOI: 10.1016/ S2352-4642(20)30108-5.

25. Tai DY. SARS plague: duty of care or medical heroism? Ann Acad Med 2006;35:374-378. PMID: 16830007.

26. Alsubaie S, Hani Temsah M, Al-Eyadhy AA, Gossady I, Hasan GM, Al-Rabiaah A, et al. Middle East Respiratory Syndrome Coronavirus epidemic impact on healthcare workers' risk perceptions, work and personal lives. J Infect Dev Ctries 2019;13(10):920-926. DOI: 10.3855/ jidc.11753.

27. Sokol D. Virulent epidemics and scope of healthcare workers' duty of care. Emerg Infect Dis 2006;12:1238-1241. DOI: 10.3201/ eid1208.060360.

28. Malm H, May T, Francis LP, Omer SB, Salmon DA, Hood R. Ethics, pandemics, and the duty to treat. Am J Bioeth 2008;8(8):4-19. DOI: 10.1080/15265160802317974.

29. Hopkins Bloomberg J, Roberton T, Carter ED, Chou VB, Stegmuller $A R$, Jackson $B D$, et al. Early estimates of the indirect effects of the
COVID-19 pandemic on maternal and child mortality in low-income and middle-income countries: a modelling study. Lancet Glob Health 2020;8:e901-e908. DOI: 10.1016/S2214-109X(20)30229-1.

30. Thornton J. Covid-19: A\&E visits in England fall by $25 \%$ in week after lockdown. BMJ 2020;369:m1401. DOI: 10.1136/bmj.m1401.

31. Willan J, King AJ, Djebbari F, Turner GDH, Royston DJ, Pavord S, et al. Assessing the impact of lockdown: fresh challenges for the care of haematology patients in the COVID-19 pandemic. $\mathrm{Br} J$ Haematol 2020;189(6):e224-e227. DOI: 10.1111/bjh.16782.

32. Lippi G, Henry BM, Bovo C, Sanchis-Gomar F. Health risks and potential remedies during prolonged lockdowns for coronavirus disease 2019 (COVID-19). Diagnosis 2020;7(2):85-90. DOI: 10.1515/dx-2020-0041.

33. Ivanov D. Predicting the impacts of epidemic outbreaks on global supply chains: a simulation-based analysis on the coronavirus outbreak (COVID-19/SARS-CoV-2) case. Transp Res Part E Logist Transp Rev 2020;136:101922. DOI: 10.1016/j.tre.2020.101922.

34. Govt. nod to private labs for COVID-19 testing likely soon. The Hindu. Available from: https://www.thehindu.com/news/cities/ Hyderabad/govt-nod-to-private-labs-for-covid-19-testing-likelysoon/article31717826.ece. Accessed 9 July 2020.

35. India's high use of antigen tests risks underestimating COVID19 spread, says diagnostician. Reuters. Available from: https:// in.reuters.com/article/health-coronavirus-india-tests/indias-highuse-of-antigen-tests-risks-underestimating-covid-19-spread-saysdiagnostician-idINKBN27D2LX. Accessed 31 December 2020.

36. Wyatt JC. When to use web-based surveys. J Am Med Inform Assoc 2000;7:426-430. DOI: 10.1136/jamia.2000.0070426.

37. Burns KEA, Duffett M, Kho ME, Meade MO, Adhikari NKJ, Sinuff T, et al. A guide for the design and conduct of self-administered surveys of clinicians. CMAJ 2008;179(3):245-252. DOI: 10.1503/cmaj.080372.

38. Eysenbach G. Improving the quality of web surveys: the checklist for reporting results of internet e-surveys (CHERRIES). J Med Internet Res 2004;6(3):e34. DOI: 10.2196/jmir.6.3.e34.

39. Jones TL, Baxter M, Khanduja V. A quick guide to survey research. Ann R Coll Surg Engl 2013;95(1):5-7. DOI: 10.1308/003588413X13511 609956372.

40. Mafham MM, Spata E, Goldacre R, Gair D, Curnow P, Bray M, et al. COVID-19 pandemic and admission rates for and management of acute coronary syndromes in England. Lancet 2020;396(10248): 381-389. DOI: 10.1016/S0140-6736(20)31356-8. 